\title{
BURNT AND UNBURNT CARBON: DATING CHARCOAL AND BURNT BONE FROM THE WILLANDRA LAKES, AUSTRALIA
}

\section{RICHARD GILLESPIE}

\author{
Dizzy Heights, Ripps Road, Stokers Siding NSW 2484, Australia
}

\begin{abstract}
A new analysis of previous results on conflicts between shell and charcoal dates and on burnt human bones, with new data presented here, suggests that alternative interpretations are possible for the archaeology and environmental history of the Willandra Lakes region. Black sediment samples from archaeological sites at Lake Outer Arumpo exhibit wide variation in burnt and unburnt carbon content; high humic acid concentrations in midden layers and in one group of hearth/ ovens are absent in another, older, group of hearth/ovens. There are no acceptable results on charcoal from hearth/ovens older than ca. $31 \mathrm{ka} \mathrm{BP}$, and no evidence that these samples are associated with numerous midden shell dates at 34-37 ka BP. Similar logic applied to humic-free residue dates on burnt human bones places five gracile skeletons (including Mungo 1) as postLast Glacial Maximum.
\end{abstract}

\section{INTRODUCTION}

The Willandra Lakes region of southwestern New South Wales, Australia (Fig. 1), contains an extensive record of human occupation and major environmental change, brought to prominence by the discovery of human burials eroding out from eolian lunette sediments at Lake Mungo (Bowler et al. 1970; Bowler, Thorne and Polach 1972; Bowler and Thorne 1976). Dating of the archaeological remains, and the sediments in which they are contained, has been based largely on radiocarbon in lacustrine shells and charcoal, with some thermoluminescence (TL) in quartz. More than $200{ }^{14} \mathrm{C}$ measurements on Willandra samples are split evenly between biological carbonates (lacustrine shell and fish otolith, emu eggshell) and organic carbon (mainly described as charcoal). Charcoal excavated from features considered to be aboriginal hearths, ovens or fireplaces has yielded dates that in some cases conflict with apparently associated shells; the shell dates are invariably older and considered more reliable than charcoal (Bowler 1976, 1986; Hope 1993; Johnston 1993). The work reported here addresses this charcoal/shell problem, and related difficulties in dating the skeletons, from a chemical pretreatment perspective.

Samples processed for this work include those selected by Isabel McBryde, from materials too small for conventional radiometric measurement, collected during her excavations at Top Hut sites on the Outer Arumpo lunette in 1974-1975, supplemented with samples collected in 1991 by the author with John Magee, Peter Clark and Roddy Smith from locations near those excavated by McBryde. Burnt human bone samples were selected on the basis of carbon content from the Willandra collections analyzed by Webb (1989), where the dates were reported with a different interpretation that I now consider logically flawed and incorrect. Other dates on Willandra samples consulted for this analysis are from a comprehensive list compiled by Clark (1987); unpublished results from John Head, Isabel McBryde and Jim Bowler; and a set of fish otolith results from Kalish et al. (1997).

\section{METHODS}

Shell, fish otolith and emu eggshell samples were etched with dilute acid at reduced pressure to remove $c a$. $50 \%$ of total carbonate prior to $\mathrm{CO}_{2}$ collection. Black sediment and charcoal samples were treated with dilute $\mathrm{HCl}$ to dissolve carbonates, then hand picked and washed through sieves to collect black lumps larger than $180 \mu \mathrm{m}$; in most cases, further separation was achieved by flotation (using sodium polytungstate solution of specific gravity 2.0 ) and demineralization with $\mathrm{HF} / \mathrm{HCl}$. These small black particles were then given a standard acid/alkali/acid pretreatment sequence, or were oxidized with hot $70 \%$ nitric acid, or room temperature $35 \%$ nitric acid with the addition of 


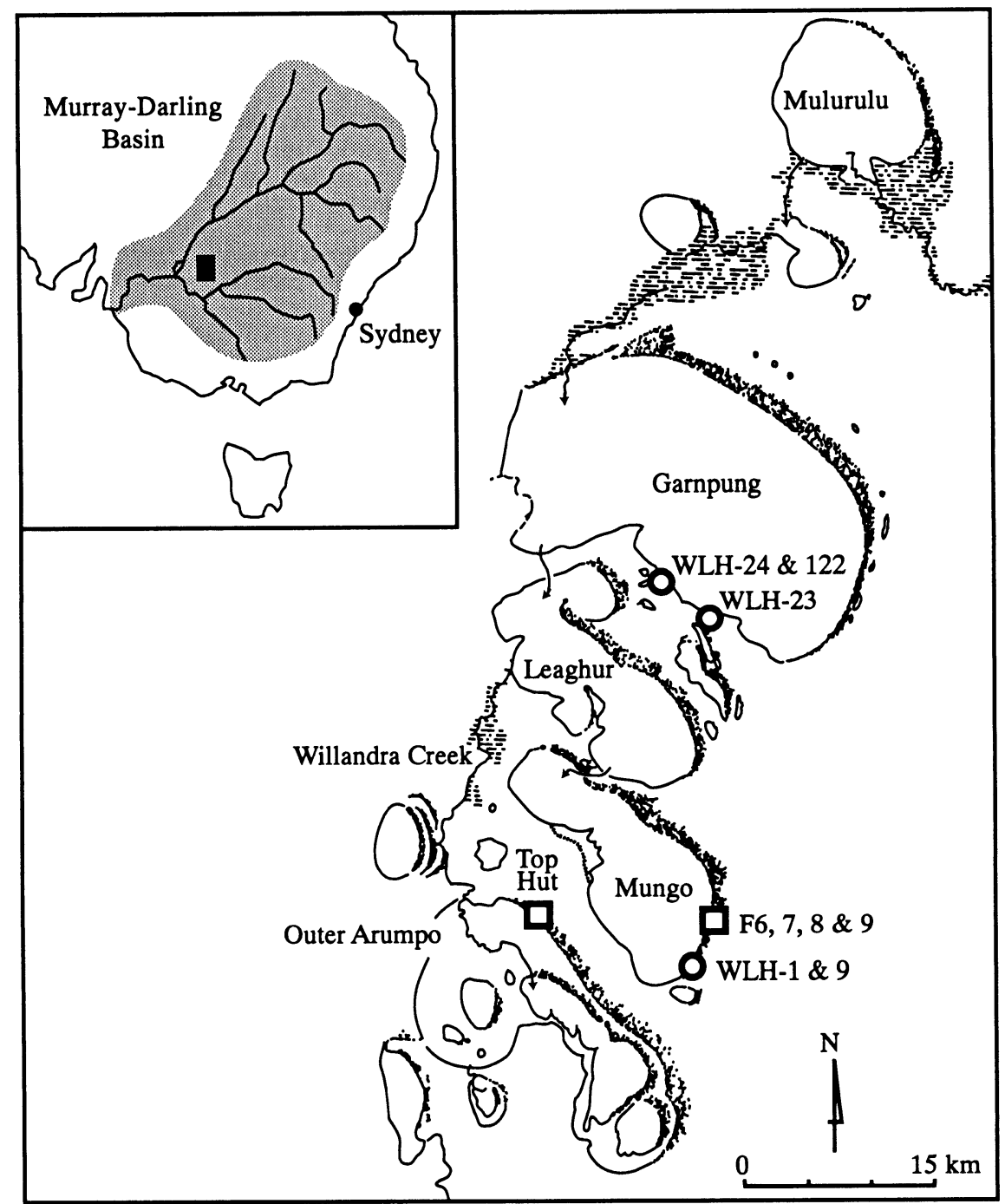

Fig. 1. Map of the Willandra Lakes region showing locations of samples discussed in the text, with inset of southeastern Australia and the Murray-Darling Basin, modified after Webb (1989)

$10 \%$ potassium chlorate, for $1 \mathrm{~h}$. After oxidation, the residue was extracted with an alkaline reagent, either $5 \%$ ammonia or $0.1 \mathrm{M}$ sodium hydroxide/pyrophosphate, to extract humic acids and other components rendered soluble by the oxidation treatment. The final oxidation-resistant, humic-free organic residue was washed again with acid and then water. Burnt bones were treated with dilute acid for demineralization, followed by alkali extraction and finally acid and water washes. In some cases, a humic acids fraction was collected for separate measurement by reacidification of the alkali extract from charcoal or burnt bone. Combustion of the organic samples was carried out in sealed evacuated silica tubes, with copper oxide and silver wire, at $900^{\circ} \mathrm{C}$ for $1 \mathrm{~h}$. For comparison with previous work on organic materials, a three-stage decontamination of increasing strength is proposed:

\footnotetext{
Stage 1 Acid wash only

Stage 2 Acid/alkali/acid

Stage 3 Acid oxidation/alkali/acid.
} 
Laboratory work for all samples in the date list below, up to and including $\mathrm{CO}_{2}$ collection from combustion or acid hydrolysis, was carried out by the author at the Division of Archaeology and Natural History, ANU. Gas samples were sent to the Lawrence Livermore or New Zealand AMS facilities for conversion to graphite and measurement by standard methods.

\section{RESULTS AND DISCUSSION}

Chemical processing similar to that employed in this work has been widely used for concentrating pollen, and charcoal particles of similar size, from Australian sedimentary deposits (e.g., Singh and Geissler 1985; Kershaw 1986); the essential steps seem to be demineralization, acid oxidation and alkali extraction. Studies on charcoal from alluvial and lacustrine sediments have shown that acid oxidation releases more humic material after a standard alkali extraction, and suggest that such pretreatment leads to more consistent chronologies (Gillespie 1990; Gillespie et al. 1991, 1992). Both nitric acid and dichromate methods have been used to decontaminate, or to determine total oxidizable carbon in, buried charcoals, of which humic acids represent on average only $50 \%$ of that total (Shultz 1962; Goh 1978; Goh and Molloy 1979). The Schollenberger (1945) variation of a common acid/dichromate method has been employed for carbon analysis in rock skins, with a weaker oxidation by dilute acid/permanganate to specifically remove oxalate for dating (Gillespie 1997).

Bird and Grocke (1997) used acid/permanganate and alkali/peroxide reagents to demonstrate the reproducible isolation of oxidation-resistant, elemental carbon from charcoal and fine-grained sediments, which retains the isotopic signature of the plant that was burnt. Charcoal prepared by pyrolysis of $\mathrm{C}_{3}$ wood, and robust $\mathrm{C}_{4}$ plant material such as corn cobs and sugar cane stalks, was more resistant to oxidation than carbonized leaves or grasses. Noncellular organic materials such as humic acids are most easily oxidized. In semiarid Australia, there are no woody $\mathrm{C}_{4}$ plants, so in sediments with mixed $\mathrm{C}_{3} / \mathrm{C}_{4}$ sources, the easily oxidized components from leaves and $\mathrm{C}_{4}$ grasses or shrubs will tend to be eliminated, and $\mathrm{C}_{3}$ wood charcoal favored, during processing.

Such chemical oxidation techniques distinguish between burnt carbon (charcoal) and unburnt carbon (everything else): the standard alkali extraction removes the humic acids component of unburnt carbon; oxidation accelerates the natural processes of humification by rendering cellular material into smaller, alkali-soluble fragments. Very little cellular material survives in the Willandra Lakes region (there are no pollen charts), so that although the nitric acid-based reagents used here are less effective than dichromate or permanganate methods for the oxidation of unburnt plant material, it seems justifiable to assume that separation of burnt from unburnt carbon has been achieved. For archaeological hearth/oven samples, the objective is to date the time of a fire from measurements of carbon isotope ratios, which are fixed by the burning event to average values present in the living plant. Thus, oxidation-resistant burnt wood carbon reasonably describes what is generally thought of as charcoal and is the most desirable sample material for dating a fire.

Although the date list below shows Conventional Radiocarbon Ages as defined by Stuiver and Polach (1977), it is necessary to calibrate the dates for comparison with dates from other methods. In this analysis, a calibration curve based on U/Th series and ${ }^{14} \mathrm{C}$ dates on coral (Bard et al. 1990, 1993, as employed by Miller, Magee and Jull 1997) has been used. The second-order polynomial derived from these data indicates increasing correction to ${ }^{14} \mathrm{C}$ dates with age, reaching $4500 \mathrm{yr}$ at $c a$. $40 \mathrm{ka} \mathrm{BP}$, although ${ }^{14} \mathrm{C}$ production rates based on geomagnetic data suggest that decreasing correction in the range 35-45 ka BP may be likely (Laj, Mazaud and Duplessy 1996). Calibrated dates will be used throughout this discussion, with the Last Glacial Maximum period at 20-25 cal ka BP as a reference. An error multiplier of 1.5 has been applied to dates plotted in Figures 2 and 3, to account for laboratory variations and uncertainty in the calibration. 


\section{Shells, Fish and Emus}

Shells from the freshwater bivalve Velesunio ambiguus have been considered to provide the most reliable ${ }^{14} \mathrm{C}$ dates because of consistent results from sites of similar stratigraphic location. No contamination problem resulting from carbonate recrystallization has been reported in these aragonitic shells, and no reservoir effect is expected because the region is free from geological-age limestone (Bowler 1976, 1986), although both of these assumptions await definitive experimental proof. In the case of aragonitic otoliths from the freshwater fish Macquaria ambigua, widely distributed in Willandra archaeological sites, demonstration is also required that these factors are absent or insignificant for the lacustrine environment. For the low-Mg calcite in Dromaius sp. emu eggshell, Miller, Magee and Jull (1997) have shown that equilibrium with atmospheric carbon isotope ratios is adequately confirmed and that these dates are reliable. Because of similar dates from similar locations for all three of these robust single-component biological carbonates, it seems reasonable to conclude that dates on these materials are accurate, and none are rejected.

As a first approximation for this analysis, ignoring both archaeology and stratigraphy, dates are simply sorted according to age and plotted as cumulative frequencies. Figure $2 \mathrm{~A}$ shows the distribution of dates on lacustrine shells and fish otoliths, separated into two groups by location: samples from the northern lakes Leaghur, Garnpung and Mulurulu, and those from the two southern lakes Mungo and Outer Arumpo. Not shown are shell samples collected from in situ growth positions on lake floors, which indicate that Mungo was dry at $17 \mathrm{cal} \mathrm{ka} \mathrm{BP} \mathrm{(N-1656),} \mathrm{and} \mathrm{both} \mathrm{Mungo} \mathrm{and} \mathrm{Outer}$ Arumpo were dry at $42-43$ cal ka BP (ANU-306, 4134). Between these end points, 41 shell and fish dates from all lakes fall in a $\mathbf{3 0 0 0}$ yr range immediately following Last Glacial Maximum. Before LGM, there are north/south differences in age distribution, with a 14-sample group from Mungo and Outer Arumpo in the range 37-41 cal ka BP. The distribution of emu eggshell dates, also shown in Figure 2A, suggests that lake water levels were not critical for the presence of emus in the Willandra.

\section{Charcoal}

During the processing of samples from the Top Hut 1 complex of sites on the Outer Arumpo lunette, qualitative differences were apparent between hearth/oven groups: samples from Hearth 1 contained abundant humic acids (comprising $>90 \%$ of the total carbon) and calcrete heat retainers, whereas Hearths 2 and 4 samples had very little humic contamination and baked earth heat retainers. Clark and Barbetti (1982) also noted a lack of datable charcoal in Willandra hearth/ovens with calcrete. The humic-free, Stage 2 or 3 residues from Hearth 2 (CAMS-2039, 2040 and 2041), and from Hearth 4 (CAMS-2042), each contained a few milligrams of charcoal, identifiable under 10x binocular magnification by the shiny black facets and three-dimensional architecture characteristic of burnt wood charcoal. These samples are clearly acceptable. For Hearth 1, one Stage 3 residue contained no identifiable charcoal in a very small sample (CAMS-2872, $<0.5 \mathrm{mg}$ carbon per $100 \mathrm{~g}$ sediment) and is rejected. Two other samples from the same hearth/oven had borderline charcoal $(\sim 1$ mg per $100 \mathrm{~g}$ ), provisionally acceptable because of demonstrated removal of humic acids (CAMS2873,2874 and 2875). Four other samples measured from these locations are also rejected because of very small, unidentifiable residues of dubious origin.

Almost all charcoal samples from the Mungo lunette listed by Clark (1987), processed in the early 1970 s, were given only a Stage 1 acid treatment. Of many results rejected, particular note is made of ANU-1263 ( $>40 \mathrm{ka} \mathrm{BP}$ ) from the Mulvaney excavation at Mungo-a very small sample, this was given minimal Stage 1 treatment and counted for an unusually short time, and consequently could not be distinguished from machine background. This is not a valid ${ }^{14} \mathrm{C}$ date and needs to be removed 


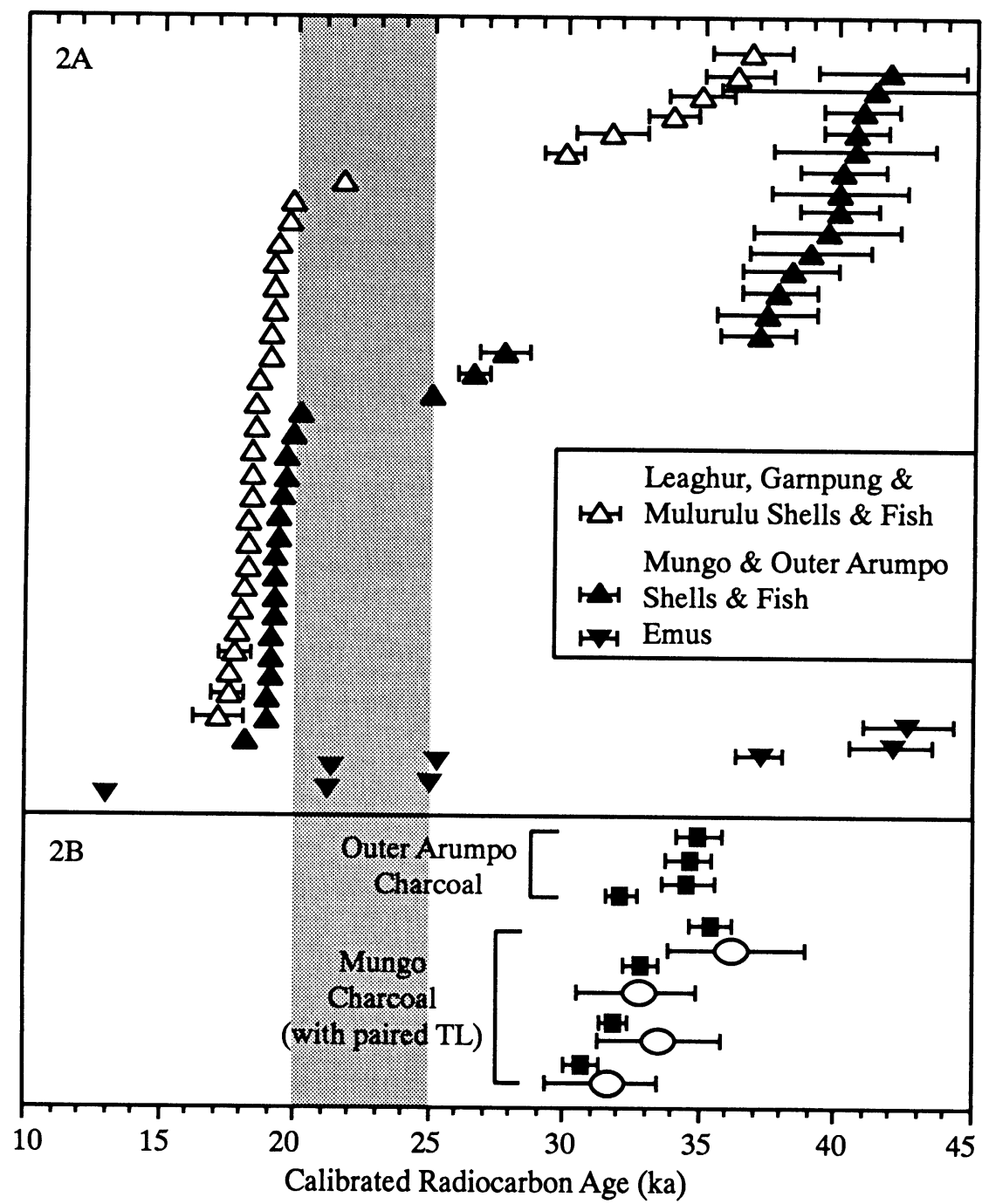

Fig. 2. A. Willandra shell, fish otolith and emu eggshell dates, plotted as cumulative frequency in order of age. Data from Clark (1987); Kalish et al. (1997); Miller, Magee and Jull (1997); J. Head (personal communication 1992); and the present study. B. Acceptable charcoal dates from Outer Arumpo (the present study) and Mungo (Barbetti and Polach 1973), with paired TL dates on quartz from the same Mungo sites (Bell 1991). The shaded region represents Last Glacial Maximum.

from the record. There is, however, independent evidence from TL that one group of charcoals sampled from Mungo hearth/ovens containing baked earth heat retainers is reliably dated by ${ }^{14} \mathrm{C}$. Four charcoal ${ }^{14} \mathrm{C}$ dates from samples at the geomagnetic site (Barbetti and Polach 1973; Barbetti and Flude 1979) overlap in age with TL dates on quartz from the same hearths (F6, 7, 8 and 9; Bell 1991). In this example, the fire that produced the charcoal also bleached the TL signal, so the two methods are estimating a date for the same event. These Mungo results are plotted with the Top Hut 1, Hearth 2 and 4 charcoal results from Outer Arumpo in Figure 2B, as the oldest acceptable Willandra organic carbon dates. 


\section{The Shell/Charcoal Problem}

Previous results on midden shell samples have yielded dates significantly older than those from charcoal samples from the same locations (Bowler et al. 1970; Barbetti and Allen 1972; Bowler, Thorne and Polach 1972; Hope 1993; Johnston 1993). Charcoal dates are younger than shell dates by a variable amount, increasing with age to several thousand years in the period beyond $30 \mathrm{cal} \mathrm{ka}$ BP, whereas shell dates appear to be consistent for deposits in similar stratigraphic locations throughout the region. These conflicts are most apparent in samples from the Outer Arumpo lunette, where the oldest acceptable charcoal dates at 32-35 cal ka BP are significantly younger than the oldest group of shell and fish dates at 39-41 cal ka BP.

Three issues relating to this problem point toward possible solutions. One major concern with these Outer Arumpo sites is the lack of recognizable charcoal in black sediments from the shell layers at Top Hut $1 \mathrm{M}$ and $3 \mathrm{M}$, and in hearth/oven samples from Top Hut 1, Hearth 1 . Samples from these locations contain $>90 \%$ humic acids and virtually no oxidation-resistant burnt carbon residue; thus, there is insufficient evidence that a local fire has produced suitable charcoal for dating that fire. It is possible that the humic acids component could have been derived from plant material originally used for the fire, but there is no published demonstration of this and no good reason to accept dates on samples dominated by humic acids.

A second concern is the function of hearth/ovens: Top Hut 1, Hearths 1, 2 and 4 have features described as similar to recent pit ovens used for cooking large game such as kangaroo (McBryde n.d.). Techniques used to process marine and estuarine shellfish described by Meehan (1982) include a quick method (used near the collection site) with a small fire of leaves and twigs on top of live shellfish placed on edge in sand, followed by removal of the cooked shellfish for cooling on a bed of leaves, and a more elaborate hearth method in which a large fire containing large branches and dead shells is allowed to burn down to coals before the live shellfish are placed on top and covered with leaves and bark. The quick method is unlikely to leave any charcoal or shells at the cooking site, the hearth method may introduce older shells into the cooking site, and both methods may involve transport of both live and cooked shellfish some distance from the collection and cooking sites. If similar methods were employed in the Willandra to process Velesunio shells, there is no good reason to expect that shells are necessarily associated with pit ovens.

The third major concern arises from the nature of pit ovens, which perforce are dug into older lunette sediments, near the surface exposed at the site when the hearth/oven was constructed. Consequently, charcoal samples found at the bottom of such pits may well be at the same level as older, unrelated shell middens. At times of low lake water levels, clay-rich eolian sediment transported to the lunette from the lake floor will also contain detrital organic materials from lacustrine flora and fauna. In archaeological sites with shells or calcrete in close proximity to hearth/ovens, a disturbed alkaline environment allows soluble humic acids to move through the sediments for adsorption onto porous charcoal. At the Top Hut 1 and 3 locations, three out of four humic acids dates are significantly older than the insoluble residues from which they were extracted. The oldest humic acids dates overlap with the oldest shell dates, suggesting that midden shells and their enclosing sediment are likely sources of carbon for the mobile humic acids.

These three factors - little charcoal with high humic content, methods of shellfish cooking and pits dug into older sediments - may contribute, singly or in combination, to the observed shell/charcoal difficulties and suggest that expectations of association are misplaced. (Dates from the Top Hut sites are plotted in Figure 3A.) 


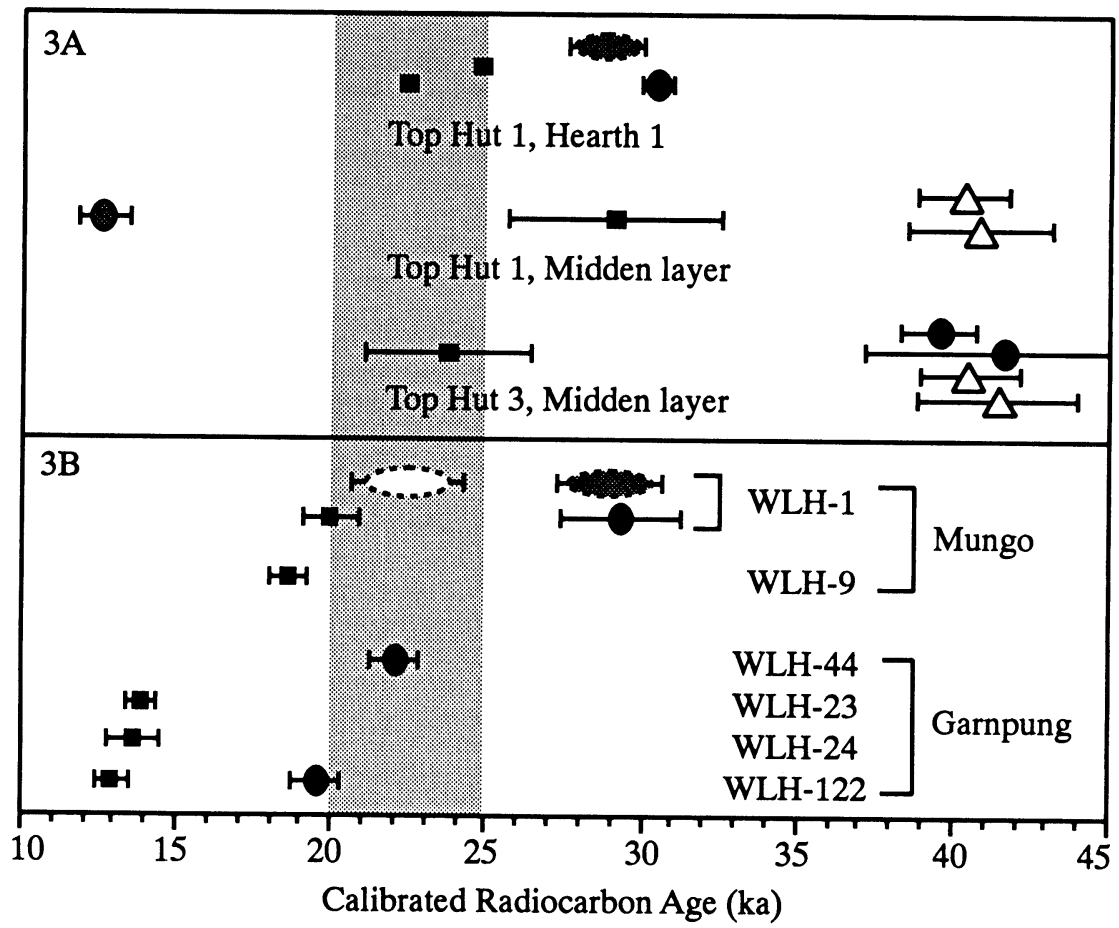

Fig. 3. A. Outer Arumpo samples of humic-free residues ( $\square$ ), humic acids ( $\bigcirc$ ), acid insoluble residues ( ) and shells $(\triangle)$; from J. Head (personal communication 1992) and this work, showing the shell/charcoal problem. B. Burnt human bones from Mungo and Garnpung. Symbols as in (A), plus bone apatite ( $\because \because)$; from Webb (1989) and Bowler, Thorne and Polach (1972). The shaded region represents Last Glacial Maximum.

\section{Human Burials}

Estimates for the age of skeleton WLH-1 (also known as Mungo 1, the first of more than 100 found in the Willandra Lakes region) vary widely, from $23-29 \mathrm{cal} \mathrm{ka} \mathrm{BP}$ to beyond ${ }^{14} \mathrm{C}$ range (Bowler, Thorne and Polach 1972; Bowler and Price 1997). The original dates for WLH-1, on bone apatite and Stage 1 acid washed samples of burnt bone, are unacceptable: apatite is known to exchange carbon, and here is similar in age to soil carbonate from nearby locations (ANU-618A, 375A), while the Stage 1 residue (ANU-618B) has now been shown to consist mostly of humic acids (Webb 1989 and the present study).

Six burnt bone samples were processed using standard Stage 2 chemistry; in both cases where residues and humic acids were separately measured, for skeletons WLH-1 and WLH-122, the humic fraction is significantly older than the insoluble residue (NZA-230, 231 and 246; NZA-164, 194) and contains $>90 \%$ of the total organic carbon; for WLH- 44 all organic carbon was soluble in alkali. All five insoluble residue samples have $\delta^{13} \mathrm{C}$ values of -18.9 to $-20.5 \%$, within the range of values found in unburnt human bone collagen of Holocene age from the Murray-Darling Basin (Pate 1997). The significantly different $\delta^{13} \mathrm{C}$ value of $-15.5 \%$ measured in humic acids from WLH-122 suggests a different source of carbon for the soluble component. Issues of concern for charcoal, such as burial in older, calcareous, alkaline sediments and the mobility of humic acids in such environments, apply equally well to these burnt bone samples, and the older humic acids dates must still be rejected. With 
charcoal and burnt bone, humic acids are regarded as contaminants regardless of relative age-if the humic dates are younger, the residue age is a minimum age estimate, but if humic acids are older than the residues, logic demands that incomplete removal will lead to maximum age estimates for these Willandra samples. Older humic acids fraction dates seem to occur in disturbed, fine-grained, calcareous sediments from semiarid regions (Batten et al. 1986; Gowlett and Hedges 1987; Geyh et al. 1983).

If only the Stage 2, acid and alkali insoluble residue dates are accepted, as proposed for the charcoal samples above, two skeletons from the Mungo lunette are placed at 18-20 cal ka BP (WLH-1 and 9), and three skeletons from the southwestern shores of Garnpung are placed at 13-14 cal ka BP (WLH23, 24 and 122). The Mungo burials are dated on this analysis in the same range as a large number of mainly surface-collected fish otoliths and shells (Fig. 2A), whereas the Garnpung burials postdate drying out of the lakes. These bone dates are plotted in Figure 3B for comparison with the shell/ charcoal results.

\section{CONCLUSION}

Some of the dates presented here, particularly the post-Last Glacial Maximum age for Mungo 1 bones, depart significantly from accepted wisdom for the Willandra Lakes. Burnt bone is similar in behavior to charcoal under alkali extraction pretreatment because of similar high surface area and porous structures. By taking as a basic premise that humic acids dates are irrelevant to dates on burnt wood charcoal or burnt bone, a consistent pattern can be found in ${ }^{14} \mathrm{C}$ measurements on Willandra Lakes materials. In noncalcareous hearth/oven sites, charcoal dates are as reliable as the robust, single-component, faunal carbonate dates. What little recognizable charcoal has been found in midden and calcareous hearth/oven sites is certainly much younger than nearby shells, and on the evidence presented here the shells and charcoal should not be associated. This suggests that some of the oldest shell layers at Outer Arumpo may be natural deposits. Possible sources for the unburnt carbon in humic acids fractions include shell protein from middens and lake floor organics attached to clayrich eolian sediments carried to lunette sites during periods of low lake water levels, mobilized by alkaline environments that have undergone large-scale hydrologic change.

Similar issues are relevant for the human burials, and removal of unburnt humic acids carbon yields residue dates significantly younger than previous estimates, but not inconsistent with the regional record. The five directly dated burnt human bones, all exhibiting gracile morphology, are placed as post-Last Glacial Maximum. Three skeletons from Garnpung are in the same age range as the robust skeletons from Kow Swamp (Thorne and Macumber 1972), and since similar numbers of both gracile and robust skeletons are recorded at Garnpung (Webb 1989), it seems probable that both groups were present in the same region at the same terminal Pleistocene time.

\section{ACKNOWLEDGMENTS}

I thank Jim Bowler and John Magee for guidance in Willandra stratigraphy, Isabel McBryde for samples and for funding the dates through the Australian Research Council, Gill Atkin and Lois Taylor for technical assistance, John Chappell for laboratory facilities, and Rodger Sparks and John Southon for the AMS measurements. John Head, Jim Bowler, Isabel McBryde, Peter Clark and John Kalish kindly allowed use of their unpublished data. 


\section{ArChaeological dates}

OUTER ARUMPO LUNETTE, WILLANDRA LAKES

Top Hut 1, Area 1, Hearth 1

CAMS-2873

Charcoal

AD line 17-36 cm, 0-5 cm below surface; Stage 3 residue.

CAMS-2874

Humic acids from CAMS-2873

CAMS-2875

Charcoal

AD line $68-86 \mathrm{~cm}, 19-24 \mathrm{~cm}$. below surface; Stage 3 residue.

\section{Top Hut 1, Area 2, Hearth 2}

\section{CAMS-2041}

Charcoal

Sample 5a, 0-5 cm below surface; Stage 2 residue.

CAMS-2039

Charcoal

$20-25 \mathrm{~cm}$ below surface; Stage 2 residue.

CAMS-2040

Charcoal

Same sample as CAMS-2039; Stage 3 residue.

\section{Top Hut 1, Area 3, Hearth 3 area}

CAMS-1929

Emu eggshell

Surface collection, square A7.

CAMS-1930

Fish otolith

Surface collection, square B6.

Top Hut 1, Area 4, Hearth 4

CAMS-2042

Charcoal

Spit 3; Stage 2 residue.

Top Hut 1, Midden Layer

CAMS-2038

Velesunio shell

\section{Top Hut 3, Midden layer}

CAMS-1925

Velesunio shell
$18,800 \pm 150$

est. $\delta^{13} C=-25 \pm 2 \%$ o

$26,630 \pm 350$

est. $\delta^{13} C=-25 \pm 2 \%$

$20,880 \pm 180$

est. $\delta^{13} C=-25 \pm 2 \%$ o

$27,570 \pm 400$

est. $\delta^{13} \mathrm{C}=-25 \pm 2 \%$ o

$\mathbf{3 0 , 3 8 0} \pm \mathbf{5 5 0}$

est. $\delta^{13} C=-25 \pm 2 \%$ o

$30,030 \pm 630$

est. $\delta^{13} C=-25 \pm 2 \%$ o

$21,140 \pm 190$

est. $\delta^{13} C=-11 \pm 2 \%$ o

$21,190 \pm 190$

est. $\delta^{13} C=-6 \pm 2 \%$ o

$\mathbf{3 0 , 0 5 0} \pm \mathbf{5 3 0}$

est. $\delta^{13} C=-25 \pm 2 \%$ o

$36,170 \pm 1110$

est. $\delta^{13} C=-6 \pm 2 \%$ o

$35,590 \pm 990$

est. $\delta^{13} C=-6 \pm 2 \%$ 
CAMS-1922

$34,580 \pm 860$

Humic acids from CAMS-1920

est. $\delta^{13} C=-25 \pm 2 \%$

Ammonia extraction.

CAMS-1923

Humic acids from CAMS-1920

$34,540 \pm 820$

Sodium hydroxide/pyrophosphate extraction.

est. $\delta^{13} C=-25 \pm 2 \%$

Comment: CAMS-1922, 1923 and 1925 all from the same bulk sample of black sediment enclosing the shells, $>95 \%$ of total organic carbon present as humic acids.

LAKE MUNGO LUNETTE, WILLANDRA LAKES

NZA-231

Burnt bone; Stage 2 residue

$16,940 \pm 635$

Skeleton WLH-1 (Mungo 1)

$\delta^{13} C=-19.0 \%$

NZA-230

$25,120 \pm 1380$

Humic acids from NZA-231

est. $\delta^{13} \mathrm{C}=-19 \pm 2 \%$ o

NZA-246

Humic acids from NZA-231, repeat

$24,750 \pm 2400$

NZA-160

Burnt bone; Stage 2 residue

Skeleton WLH-9.

est. $\delta^{13} \mathrm{C}=-19 \pm 2 \%$

$15,780 \pm 430$

$\delta^{13} C=-20.5 \%$

Comment: Both burials are from southern end of the L. Mungo lunette.

LAKE GARNPUNG, WILLANDRA LAKES

NZA-163

$11,910 \pm 325$

Burnt bone; Stage 2 residue

$\delta^{13} C=-19.3 \%$

Skeleton WLH-24

NZA-165

Burnt bone; Stage 2 residue

$11,690 \pm 580$

Skeleton WLH-23

$\delta^{13} C=-19.9 \%$

NZA-194

$11,100 \pm 370$

Burnt bone; Stage 2 residue

$\delta^{13} C=-18.9 \%$

Skeleton WLH-122

NZA-164

Humic acids from NZA-194

$16,540 \pm 535$

$\delta^{13} C=-15.5 \%$

NZA-159

$18,640 \pm 530$

Humic acids from burnt bone

$\delta^{13} C=-20.8 \%$

Skeleton WLH-44.

Comment: These three burials are from southwestern shores of L. Garnpung, not the lunette.

\section{BACKGROUND SAMPLES}

CAMS-2035

Axel Heiberg wood; Stage 2 residue.

$44,000 \pm 580$

est. $\delta^{13} C=-25 \pm 2 \%$ o 
CAMS-2036

Axel Heiberg wood; Stage 3 residue.

$38,860 \pm 230$

est. $\delta^{13} \mathrm{C}=-25 \pm 2 \% 0$

$44,090 \pm 300$

CAMS-1926

Marble, IAEA C1, acid etched.

\section{REFERENCES}

Barbetti, M. and Allen, H. 1972 Prehistoric man at Lake Mungo, Australia, by 32,000 years BP. Nature 240: 46-48.

Barbetti, M. and Flude, K. 1979 Geomagnetic variation during the late Pleistocene period and changes in the radiocarbon timescale. Nature 279: 202-205.

Barbetti, M. and Polach, H. A. 1973 ANU Radiocarbon Datelist V. Radiocarbon 15(2): 241-251.

Bard, E., Hamelin, B, Fairbanks, R. G. and Zindler, A. 1990 Calibration of the ${ }^{14} \mathrm{C}$ timescale over the last 30,000 years using mass spectrometric U-Th ages from the Barbados corals. Nature 345: 587-592.

Bard, E., Arnold, M., Fairbanks, R. G. and Hamelin, B. $1993{ }^{230} \mathrm{Th}-{ }^{234} \mathrm{U}$ and ${ }^{14} \mathrm{C}$ ages obtained by mass spectrometry on corals. Radiocarbon 35: 191-199.

Batten, R. J., Gillespie, R., Gowlett, J. A. J. and Hedges, R. E. M. 1986 The AMS dating of separate fractions in archaeology. In Stuiver, M. and Kra, R., eds., Proceedings of the 12th International ${ }^{14} \mathrm{C}$ Conference. $\mathrm{Ra}$ diocarbon 28(2A): 698-701.

Bell, W. T. 1991 Thermoluminescence dates for the Lake Mungo Aboriginal fireplaces and the implications for radiocarbon dating. Archaeometry 33: 43-50.

Bird, M. I. and Grocke, D. R. 1997 Determination of the abundance and carbon isotope composition of burnt carbon in sediments. Geochimica et Cosmochimica Acta 61: 3413-3423.

Bowler, J. M. 1976 Aridity in Australia: Age, origin and expression on aeolian landforms and sediments. Earth Science Reviews 12: 279-310.

1986 Quaternary landform evolution. In Jeans, D. N., ed., Australia: A Geography. Volume 1, The Natural Environment. 2nd ed. Ashford, England, Sydney University Press: 177-147.

Bowler, J. M., Jones, R., Allen, H. and Thorne, A. G. 1970 Pleistocene human remains from Australia: A living site and human cremation from Lake Mungo, western New South Wales. World Archaeology 2: 3960.

Bowler, J. M. and Price, D. M. (ms.) 1997 Stratigraphic and palaeohydrologic events in the Willandra Lakes: Evidence from TL dating. In Abstracts of the conference "Quaternary Deserts and Climatic Change", University of Wollongong, Australia, 30 June-3 July 1997.

Bowler, J. M. and Thorne, A. G. 1976 Human remains from Lake Mungo: Discovery and excavation of Mungo 3. In Kirk, R. L. and Thorne, A. G., eds., The Origin of the Australians. Canberra, Australian Institute of Aboriginal Studies: 127-138.

Bowler, J. M., Thorne, A. G. and Polach, H. A. 1972 Pleistocene man in Australia: Age and significance of the Mungo skeleton. Nature 240: 48-50.

Clark, P. M. (ms.) 1987 Willandra Lakes World Heritage Area archaeological resources study. Unpublished report, Western Lands Commission, New South Wales Department of Planning, Sydney.

Clark, P. M. and Barbetti, M. 1982 Fires, hearths and palaeomagnetism. In Ambrose, W. and Duerden, P., eds., Archaeometry: An Australasian Perspective. Canberra, Department of Prehistory, Australian National University: 144-150.

Geyh, M. A., Roeschmann, G., Wijmstra, T. A. and Middeldorp, A. A. 1983 The unreliability of ${ }^{14} \mathrm{C}$ dates obtained from buried sandy podsols. In Stuiver, $\mathrm{M}$. and Kra, R. S., eds., Proceedings of the 11th International ${ }^{14} \mathrm{C}$ Conference. Radiocarbon 25(2): 409-416.

Gillespie, R. 1990 On the use of oxidation for AMS sample pretreatment. Nuclear Instruments and Methods in Physics Research B52: 345-347.

1997 On human blood, rock art and calcium oxalate: Further studies on organic carbon content and radiocarbon age of materials relating to Australian rock art. Antiquity 71: 430-437.

Gillespie, R., Magee, J. W., Luly, J. G., Dlugokencky, E., Sparks, R. J. and Wallace, G. 1991 AMS radiocarbon dating in the study of arid environments: Examples from Lake Eyre, South Australia. Palaeogeography, Palaeoclimatology, Palaeoecology 84: 333-338.

Gillespie, R., Prosser, I. P., Dlugokencky, E., Sparks, R. J., Wallace, G., and Chappell, J. M. A. 1992 AMS dating of alluvial sediments on the southern tablelands of New South Wales. Radiocarbon 34(1): 29-36.

Goh, K. M. 1978 Removal of contaminants to improve the reliability of radiocarbon dates of peats. Journal of Soil Science 29: 340-349.

Goh, K. M. and Molloy, B. P. J. 1979 Contaminants in charcoals used for radiocarbon dating. New Zealand Journal of Science 22: 39-47.

Gowlett, J. A. J. and Hedges, R. E. M. 1987 Radiocarbon dating by accelerator mass spectrometry - applications to archaeology in the Near East. In Aurenche, O., Evin, J. and Hours, F., eds., Chronologies in the Near East. BAR International Series 379. Oxford, British Archaeological Reports: 121-144.

Hope, J. 1993 Pleistocene archaeological sites in the central Murray-Darling basin. In Smith, M. A., Spriggs, M. and Fankhauser, B., eds., Sahul in Review: Pleis- 
tocene Archaeology in Australia, New Guinea and Island Melanesia. Canberra, Department of Prehistory, Australian National University: 183-196.

Johnston, H. 1993 Pleistocene shell middens of the Willandra Lakes. In Smith, M. A., Spriggs, M. and Fankhauser, B., eds., Sahul in Review: Pleistocene Archaeology in Australia, New Guinea and Island Melanesia. Canberra, Department of Prehistory, Australian National University: 197-203.

Kalish, J. M., Miller, G. H., Tuniz, C., Pritchard, J. C., Rosewater, A. and Lawson, E. (ms.) 1997 Otoliths as recorders of palaeoenvironments: Comparison of radiocarbon age and isoleucine epimerization in Pleistocene golden perch Macquaria ambigua otoliths from Willandra Lakes. Abstracts of the Sixth Australasian Archaeometry Conference, Australian Museum, Sydney, 10-13 February 1997.

Kershaw, A. P. 1986 Climatic change and Aboriginal burning in north-east Australia during the last two glacial/interglacial cycles. Nature 322: 47-49.

Laj, C., Mazaud, A. and Duplessy, J.-C. 1996 Geomagnetic intensity and ${ }^{14} \mathrm{C}$ abundance in the atmosphere and ocean during the past $50 \mathrm{kyr}$. Geophysical Research Letters 23: 2045-2048.

McBryde, I. n.d., Living floors, hearths and middens: Archaeology on the Outer Arumpo lunette, 1974-75. Unpublished draft ms.
Meehan, B. 1982 Shell Bed to Shell Midden. Canberra, Australian Institute of Aboriginal Studies: $189 \mathrm{p}$.

Miller, G. H., Magee, J. M. and Jull, A. J. T. 1997 Lowlatitude glacial cooling in the Southern Hemisphere from amino-acid racemization in emu eggshells. $\mathrm{Na}$ ture 385: 241-244.

Pate, D. 1997 Bone chemistry and palaeodiet: Reconstructing prehistoric subsistence-settlement systems in Australia. Journal of Anthropological Archaeology 16: $103-120$.

Schollenberger, C. J. 1945 Determination of soil organic matter. Soil Science 59: 53-56.

Shultz, H. (ms.) 1962 Studies in radiocarbon dating. Ph.D. thesis, Pennsylvania State University.

Singh, G. and Geissler, E. A. 1985 Late Cainozoic history of vegetation, fire, lake levels and climate, at Lake George, New South Wales, Australia. Philosophical Transactions of the Royal Society of London 311B: 379-447.

Stuiver, M. and Polach, H. A. 1977 Discussion: Reporting of ${ }^{14} \mathrm{C}$ data. Radiocarbon 19(3): 355-363

Thorne, A. G. and Macumber, P. G. 1972 Discoveries of late Pleistocene man at Kow Swamp, Australia. $\mathrm{Na}$ ture 238: 316-319.

Webb, S. G. 1989 The Willandra Lakes Hominids. Canberra, Department of Prehistory, Australian National University: $194 \mathrm{p}$. 